Journal of Information \& Knowledge Management

Vol. 15, No. 4 (2016) 1699001 (5 pages)

(C) World Scientific Publishing Co.

\title{
Author Index Volume 15
}

N. Abdelhamid see Thabtah, F.

4 (2016) 1650042

M. Abdellatif see Asma, K.

4 (2016) 1650041

N. M. Adam see Pourzolfaghar, Z.

1 (2016) 1650002

G. Adel see Tarek, B. H.

4 (2016) 1650034

N. K. Agarwal see Marouf, L. N.

3 (2016) 1650024

H. Ahmadi see Nilashi, M.

3 (2016) 1650032

S. Akça see Taşkın, Z.

4 (2016) 1650039

B. M. Alajmi, L. N. Marouf \& A. S. Chaudhry Knowledge Management for Healthcare: Investigating Practices that Drive Performance

2 (2016) 1650014

J. Albors-Garrigos, J. C. Ramos-Carrasco \& A. Peiro-Signes Actional Intelligence, a Key Element for Actioning Knowledge. A Field Study Analysis

S. M. Alhashmi see Shaikh, A. K.

S. Al-Janabi \& I. Al-Shourbaji A Study of Cyber Security Awareness in Educational Environment in the Middle East

1 (2016) 1650006

2 (2016) 1650020

1 (2016) 1650007

3 (2016) 1650032

A. Almaee see Nilashi, M.

1 (2016) 1650007

I. Al-Shourbaji see Al-Janabi, S.

K. Asma \& M. Abdellatif A New Model for the Impact of

Knowledge Management on University Performance. Part 1: Theoretical Development

4 (2016) 1650041

P. Bandyopadhyay see Sardar, S.

G. Belalem see Dahmani, D.

3 (2016) 1650026

4 (2016) 1650038

S. Bhattacharya see Gupta, P. D.

4 (2016) 1650040

G. Bruns see Durst, S.

Y. E. Chan, J. S. Denford \& J. Y. Jin Competing Through

2 (2016) 1650012

Knowledge and Information Systems Strategies: A Study of

Small and Medium-Sized Firms

3 (2016) 1650027

H.-C. Chang The Synergy of Scientometric Analysis and

Knowledge Mapping with Topic Models: Modelling the

Development Trajectories of Information Security and

Cyber-Security Research

4 (2016) 1650044

A. S. Chaudhry see Alajmi, B. M.

2 (2016) 1650014 
A. S. Chaudhry see Rehman, S.

2 (2016) 1650021

D. Dahmani, S. A. Rahal \& G. Belalem Improving the Performance of Data Mining by Using Big Data in Cloud Environment

4 (2016) 1650038

R. Darby \& C. Kirke The Development of a KIM Behavioural Framework to Support Science and Technology Knowledge Transfer in the UK Defence Sector. A Case Study Approach

I. de Sá Affonso da Costa, E. Tavares \& A. M. N. Peixoto Knowledge Creation in Hybrid Organisations: A Case Study in a Quasi-Governmental Organisation

J. S. Denford see Chan, Y. E.

C. Diriba, M. Meshesha \& D. Tesfaye Developing a Knowledge-Based System for Diagnosis and Treatment of Malaria

D. P. Donohue \& P. M. Murphy Supporting Competitive Intelligence at DuPont by Controlling Information Overload and Cutting Through the Noise

3 (2016) 1650025

3 (2016) 1650029

3 (2016) 1650027

4 (2016) 1650036

S. Durst \& G. Bruns Sustaining the Future of the Public Sector: Insights into a Swedish Municipality's Dealing with Knowledge Management and Succession Planning

1 (2016) 1650004

2 (2016) 1650012

S. Erdem, T. T. Kizilelma \& C. A. Vural Supporting Healthcare Executive Managers' Decisions Through Dashboards

N. Erhardt \& C. Martin-Rios Knowledge Management Systems in Sports: The Role of Organisational Structure, Tacit and Explicit Knowledge

R. Errattahi see Salmam, F. Z.

G. Escrivão \& M. S. Nagano Linking Knowledge Creation and Environmental Education

M. Fakir see Salmam, F. Z.

P. Galdhar see Seetharaman, A.

P. Gottschalk Knowledge Management in Criminal Investigations: The Case of Fraud Examiners

P. D. Gupta \& S. Bhattacharya Impact of Knowledge Management Processes for Sustainability of Small Family Businesses: Evidences from the Brassware Sector of Moradabad (India)

4 (2016) 1650040

B. Hasan Components of Online Shopping Attitude and the Effects of Website Design Characteristics

1 (2016) 1650005

2 (2016) 1650023

2 (2016) 1650022

2 (2016) 1650017

2 (2016) 1650022

1 (2016) 1650009

4 (2016) 1650043

M. R. Hasani see Neshat, M.

M. R. Hasani see Pourahmad, A. A.

3 (2016) 1650028

4 (2016) 1650037

1 (2016) 1650011

O. Ibrahim see Nilashi, M.

3 (2016) 1650032 
R. Ibrahim see Pourzolfaghar, Z.

1 (2016) 1650002

Y. Y. Ileri Implementation Processes of Hospital Information Management Systems: A Field Study in Turkey

3 (2016) 1650031

T. Ishida see Pariyar, A.

G. E. Iyawa A Framework for Improving Knowledge

2 (2016) 1650013 Management Practices in Namibian Software Companies

C. Jebari Multi-Label Genre Classification of Web Pages Using an Adaptive Centroid-Based Classifier

J. Y. Jin see Chan, Y. E.

1 (2016) 1650003

S.-C. Kao see $\mathrm{Wu}, \mathrm{C} . \mathrm{H}$.

1 (2016) 1650008

3 (2016) 1650027

2 (2016) 1650019

C. Kirke see Darby, R.

3 (2016) 1650025

T. T. Kizilelma see Erdem, S.

1 (2016) 1650005

D. Lin see Pariyar, A.

2 (2016) 1650013

L. N. Marouf \& N. K. Agarwal Are Faculty Members Ready? Individual Factors Affecting Knowledge Management Readiness in Universities

3 (2016) 1650024

2 (2016) 1650014

L. N. Marouf see Alajmi, B. M.

2 (2016) 1650023

M. A. Memon, K. M. Nor \& R. Salleh Personality Traits Influencing Knowledge Sharing in Student-Supervisor

Relationship: A Structural Equation Modelling Analysis

M. Meshesha see Diriba, C.

M. M. Migdadi The Role of Effective Chief Knowledge Officer in Facilitating Knowledge Management

H. Morita see Nishiguchi, M.

Y. Murakami see Pariyar, A.

P. M. Murphy see Donohue, D. P.

M. S. Nagano see Escrivão, G.

M. Neshat, A. A. Pourahmad \& M. R. Hasani Designing an Adaptive Neuro Fuzzy Inference System for Prediction of Customers Satisfaction

4 (2016) 1650037

1 (2016) 1650011

M. Nilashi, O. Ibrahim, S. Sohaei, H. Ahmadi \& A. Almaee Features Influencing Researchers' Selection of Reference Management Software

2 (2016) 1650015

4 (2016) 1650036

4 (2016) 1650035

4 (2016) 1650045

2 (2016) 1650013

1 (2016) 1650004

2 (2016) 1650017

M. Nishiguchi \& H. Morita CAECP and CRPD: Classification by Aggregating Essential Contrast Patterns, and Contrast Ranked Path Diagrams

M. Nishinaka Relations between Common Understanding and Experience: Case Study of an International Information Technology Project

K. M. Nor see Memon, M. A.

2 (2016) 1650015 
T. E. Ogunjobi \& F. O. Oyewusi Media Resources Availability and Utilisation for Effective Publication Output by Agricultural Researchers in Southwestern Nigeria

F. O. Oyewusi see Ogunjobi, T. E.

S. Panikarova \& M. Vlasov Knowledge Generation Strategies: Empirical Analysis of Industrial Enterprises

2 (2016) 1650016

2 (2016) 1650016

2 (2016) 1650018

A. Pariyar, Y. Murakami, D. Lin \& T. Ishida Information Sharing Among Countries: A Perspective from CountrySpecific Websites in Global Brands

R. Parthiban see Shaikh, A. K.

A. Peiro-Signes see Albors-Garrigos, J.

A. M. N. Peixoto see de Sá Affonso da Costa, I.

A. A. Pourahmad, M. Neshat \& M. R. Hasani Using LibQUAL Model for Improving the Level of Students' Satisfaction from Quality of Services in Academic Libraries: A Case Study in North Khorasan Province, Iran

A. A. Pourahmad see Neshat, M.

Z. Pourzolfaghar, R. Ibrahim \& N. M. Adam Explicating Mechanical and Electrical Knowledge for Design Phase of Green Building Projects

J. R. Raj see Seetharaman, A.

S. A. Rahal see Dahmani, D.

J. C. Ramos-Carrasco see Albors-Garrigos, J.

S. Rehman \& A. S. Chaudhry Health Knowledge Workers: Strategies for Literacy Development

R. Salleh see Memon, M. A.

F. Z. Salmam, M. Fakir \& R. Errattahi Prediction in OLAP Data Cubes

A. Sami see Tarek, B. H.

A. Sanyal see Sardar, S.

A. S. Saravanan see Seetharaman, A.

S. Sardar, P. Bandyopadhyay \& A. Sanyal A Comprehensive Data and Project Management Platform: A Case Study of a Central Bank

1 (2016) 1650011

4 (2016) 1650037

2 (2016) 1650013

2 (2016) 1650020

1 (2016) 1650006

3 (2016) 1650029

1 (2016) 1650002

1 (2016) 1650009

4 (2016) 1650038

1 (2016) 1650006

2 (2016) 1650021

2 (2016) 1650015

2 (2016) 1650022

4 (2016) 1650034

3 (2016) 1650026

1 (2016) 1650009

3 (2016) 1650026

A. Seetharaman, S. Singhal, P. Galdhar, J. R. Raj \&

A. S. Saravanan Customers' Expectations for Next Generation Internet Banking

1 (2016) 1650009

A. K. Shaikh, S. M. Alhashmi \& R. Parthiban A Proximity and Semantic-Aware Optimisation Model for Sub-DomainBased Decentralised Resource Discovery in Grid Computing

S. Singhal see Seetharaman, A.

1 (2016) 1650009

A. Sinha see Verma, J.

3 (2016) 1650033 
S. Sohaei see Nilashi, M.

3 (2016) 1650032

O. A. Suraj Managing Telecommunications for Development: An Analysis of Intellectual Capital in Nigerian Telecommunication Industry

1 (2016) 1650010

B. H. Tarek, G. Adel \& A. Sami Business Intelligence versus Competitive Intelligence in the Case of North African SMEs

Z. Taşkın \& S. Akça Mapping and Bibliometric Analysis of American Historical Review Citations and Its Contribution to the Field of History

4 (2016) 1650034

E. Tavares see de Sá Affonso da Costa, I.

4 (2016) 1650039

3 (2016) 1650029

D. Tesfaye see Diriba, C.

F. Thabtah \& N. Abdelhamid Deriving Correlated Sets of

4 (2016) 1650036 Website Features for Phishing Detection: A Computational Intelligence Approach

4 (2016) 1650042

J. Verma \& A. Sinha Knowledge Sharing in Cross-Functional Teams and its Antecedents: Role of Mutual Trust as a Moderator

3 (2016) 1650033

M. Vlasov see Panikarova, S.

2 (2016) 1650018

C. A. Vural see Erdem, S.

1 (2016) 1650005

C. Wu The Role of Individual Cognition, Immersion, and Knowledge Essence in Individual Knowledge Development

C.-H. Wu \& S.-C. Kao Appraisal of Knowledge Object Use via a Three-Phase Flow Profile

3 (2016) 1650030

2 (2016) 1650019

D. K. Yoo Knowledge Nurturing Reflexivity in the Lens of the Internal Conversation

1 (2016) 1650001 